\title{
The vague volcano-seismic clock of the South American Pacific margin
}

\author{
G. Scalera \\ INGV - Istituto Nazionale di Geofisica e Vulcanologia, Via Vigna Murata 605, 00143 Rome, Italy \\ Correspondence to: G. Scalera (giancarlo.scalera@ingv.it) \\ Received: 13 February 2013 - Revised: 4 June 2013 - Accepted: 7 June 2013 - Published: 13 August 2013
}

\begin{abstract}
During his trip on the Beagle, Charles Darwin wrote about the eruptions associated with the Concepción earthquake of 1835. A later survey by Lorenzo Casertano, following the great 1960 Chilean earthquake, identified some unclear evidence of a link between eruptions and the seismic event, although some reservations were also raised. Using data available in 2006 in the Smithsonian Institution Catalogue of volcanic eruptions, Scalera revealed grounded evidence that South-American Wadati-Benioff zone earthquakes of magnitudes greater than 8.4 are associated with an increased rate of volcanic eruptions, but it was still impossible to determine a causal link between the two phenomena. An average return period of about $50 \mathrm{yr}$ was deducible from the data for the time window 1800-1999. After 2006, the Smithsonian Institution's effort to improve our knowledge of this region has greatly increased the completeness of the catalogue, adding the eruptions from the 20002010 interval, together with $50 \%$ more new entries in the list of Andean volcanoes. The great Chilean Maule earthquake of 27 February $2010(M=8.8)$, occurring exactly five decades after the 1960 event, provided an occasion to reanalyse this updated database. The results suggest a preferential causal eruptions-earthquake relationship, but additional future volcano-seismic events should be studied to arrive at a definitive conclusion, within the perspective of using this phenomenon for Civil Protection. The possible correlation of South American volcano-seismic events with the Markowitz oscillation of the Polar Motion is another good reason for trying to establish an integrated geodynamic explanation.
\end{abstract}

\section{Introduction}

Plate tectonics claims the existence of a near-planar distribution of hypocenters along the Wadati-Benioff zones. Instead, the new global catalogue of relocated hypocentres (Engdahl et al., 1998) makes it possible to resolve the once blurred planar - or spoon-like - patterns of non-relocated foci into a series of clusters that narrow with increasing depth. Such unexpected characteristics make it impossible to continue sustaining the large scale subduction hypothesis (Scalera, 2007c). Consequently, possible new relations between the South American hypocentral clusters and geological surface features can be considered, and volcanic activity could be among the most important phenomena. This paper shows that, by analysing the Smithsonian Catalogue of Volcanic Eruptions, strong evidence of a correlation between Andean volcanic eruption rate and major earthquakes can be recognized.

The suspicion of a general correlation between earthquakes and eruptions goes back to ancient historical times, but regarding the Andes, a famous case is Darwin's account of the eruptions that occurred in a narrow time window around the date of the great earthquake of Concepción (Southern Chile, 20 February 1835):

[...], at the same hour when the whole country around Concepcion was permanently elevated, a train of volcanoes situated in the Andes, in front of Chiloe, instantaneously spouted out a dark column of smoke, and during the subsequent year continued in uncommon activity. It is, moreover, a very interesting circumstance, that, in the immediate neighbourhood, these eruptions entirely relieved the trembling ground, although at a little distance, and in sight of the volcanoes, the island of Chiloe was strongly affected. To the northward, a volcano burst out at the bottom of the sea 
adjoining the island of Juan Fernandez, and several of the great chimneys in the Cordillera of central Chile commenced a fresh period of activity (Darwin, 1839; p. 380).

And:

From some additional information which I have met with since finishing this chapter, I find the train of volcanic phenomena, which followed this earthquake, affected a larger area than that mentioned (seven hundred by four hundred miles), and affected it in a manner which gives great additional weight to the argument that South America is in that part a mere crust resting over a sheet of fluid rock; and likewise to the generalization that the action of volcanoes, and the permanent elevation of the land (and consequently, as I believe, the elevation of mountain chains) are parts of the same phenomenon, and due to the same cause (Darwin, 1839; in "Addenda", p. 626).

Darwin's reports are among the earliest scientifically grounded observations. Many others followed on the same subject, more or less convincingly and with wider or narrower focus (see for example Edward Hull's book, 1904). On the occasion of the great 1960 Chilean earthquake, several observations of subsequent eruptions were reported (Tazieff, 1962; Casertano, 1963; Klohn, 1963; Lara et al., 2004; among others). Casertano wrote:

Then it is probable - considering the time lapse between the earthquake and the volcanic eruption - that the action of the seismic events does not cause directly the fracturing of the zone in which the volcanic activity manifested. More likely this action was indirect, in the sense to have helped the magma - maybe already in an advanced state of eruptive potentiality - in opening its way in the zone of lesser strength (Casertano, 1962; p. 214; translated by the author).

A possible causal link between deep and intermediate earthquakes, and eruptions was envisaged by Blot in the 1960s (Blot, 1965; Blot and Priam, 1963), giving rise to further debate (Latter, 1971). Carr (1977) noted that eruptions sometimes preceded and sometime followed great seismic events, and recommended more detailed studies and implementation of seismic and eruption catalogues to improve our understanding of the causal link between the two phenomena. A longer series of papers deal with the specific problem of the triggering of eruptions by earthquakes, at different distances from the hypocentral regions (Uffen and Jessop, 1963; Latter, 1971; Barrientos, 1994; Linde and Sacks, 1998; Hill et al., 2002; Manga and Brodsky, 2006; Walter, 2007; Walter and Amelung, 2007). The possibility of earthquakes also being triggered by volcanic activity has been proposed by a small group of authors (Critikos, 1946; Kimura, 1976; Acharya, 1982; among others). Finally, the mutual influence of volcanic activity on great earthquake occurrence and vice-versa by Coulomb stress time variations, has been investigated by Nostro et al. (1998) over an extensive Southern Italian region surrounding Vesuvius.

From the perspective of physical science, at least three physical phenomena have been hypothesized as driving the interaction between volcanoes and earthquakes (Hill et al., 2002; Manga and Brodsky, 2006; Kanamori and Brodsky, 2001): static stress variations, viscoelastic relaxation, and dynamic stress induced by seismic body waves and surface waves.

- A static stress variation is transmitted after the slip of a fault or the filling or emptying of a magmatic chamber. This is a versatile process, because - depending on azimuth, dip, and position of the fault relative to the volcano - a seismic event can induce eruptions alternatively either by increasing the compression on the magma chamber, helping to squeeze it toward the surface, or by diminishing the compression with consequent development of gas bubbles that can favour the eruptive process. Conversely, eruptions or filling of magma chambers can decompress the surrounding region causing disequilibrium of fluids and favouring earthquakes and/or eruptions, or can increase existing compressive forces, triggering latent instabilities of faults and/or magma chambers.

- Viscoelastic relaxation is linked to a slow propagation of plastic deformation in the viscous upper mantle. A sudden rupture of the crust (but also the filling or emptying of a magmatic chamber) can deform the mantle immediately underlying the Moho, and the deformation can be relaxed by viscous flow of the mantle materials. This slow process can influence the occurrence of seismicity at tens of kilometres from the initial hypocenter, also triggering a concatenated series of events.

- Dynamic stress is responsible for increased rates of seismicity and eruptions at very remote distances from hypocenters of strong earthquakes. It is transmitted by seismic waves, which - albeit with very low associated stress and strain in the far-field - can modify the state of collective systems of fractures or microfractures permeated by fluids.

The above mentioned physical interaction processes are mostly considered as "final steps" with earthquakes and volcanoes thought to be mutually linked through their action (Nostro et al., 1998; Hill et al., 2002). However, it should be noted that until the first half of the 20th century a "common cause" was invoked to explain quakes and eruptions. In 1904, Hull wrote:

The connection between earthquake shocks and volcanic eruptions is now so generally recognized that it is unnecessary to insist upon it here. All volcanic districts over the globe are specially liable to vibrations of the crust; but at the same time it is to be recollected that these movements visit countries occasionally from which volcanoes, either recent or extinct, are absent; in which cases we may consider earthquake shocks to be abortive attempts to originate volcanic action. 
In the early years of the 1970s correlated sequences of earthquakes and eruptions were still hypothesized as due to a common cause, this being periods of tectonic instability and increased tensional conditions (Latter, 1971). Today the geosciences are dominated by the paradigm of plate tectonics, and a possible common cause for eruptions and quakes has been indentified as the process of subduction. This has led to acceptance of the three physical processes mentioned above as the primary causes of mutual triggering, due to the impossibility of considering sufficient the degree of the fusion and partial melting produced by friction in the very narrow slip region during a seismic event. However, bearing in mind that subduction is really only a hypothesis, other physical processes can reasonably be considered.

Due to its potential implications, an alternative conception worth scrutinizing is the non-compressional explanation for mountain building (Ollier, 2003; Scalera, 2007a, 2008). The main advantage of the non-compressional schema is the possibility of explaining major shallow earthquakes not as the subhorizontal slippage of a subducting lithosphere but as sudden vertical movements along the complementary perpendicular fault plane of the focal mechanism (Scalera, 2007c), under the forearc. This alternative interpretation suggests a common secular process involving the complete South American Pacific margin in a slowly expanding Earth framework.

\section{Reanalysis of the Smithsonian updated database}

A first analysis in 2006 of the Smithsonian Institution database for the South American Pacific margin was published in the 2007 NCGT Newsletter (Scalera, 2007b) and a report was submitted to a Joint Commission of Italian and South American scientists held in Rome in 2007 (by R. Dimaro, INGV delegate). A contribution regarding the South American volcano-seismic correlation was presented at the 2nd Humboldt Conference in Lima, Peru, 5-9 March 2007 and published next year (Scalera, 2008). The results of the Lima paper (Scalera, 2008) were purely phenomenological and did not indicate a causal link. Nevertheless, they did present the possibility (not the certainty) of a repetition of the correlation-events with an imperfect periodicity of about $45 \mathrm{yr}$.

Finally, the next volcano-seismic event occurred in 2010 (Chile, Maule, 27 February, $M=8.8$ ) and a full reanalysis using all the additional data was performed. This present paper was prepared with the aim of better defining the causeeffect link between South American eruptions and major earthquakes.

In 2006, the volcanoes list included 41 names and a total of 504 eruptions (discredited eruptions have been excluded). Today, the Smithsonian Institution database has been implemented and on the same Andean region it lists 66 volcanoes with activity from 1800 to the present time ( 25 new en-
Table 1. The number of eruptions of the Andean belt from 1800 to 2010 subdivided by decades. A comparison is made between the old Smithsonian Institution Database (Siebert et al., 2011) and the new updated data mainly used in this study. In the column on the right the difference between the new and old decadal values is displayed. In 2010 there were 11 eruptions, and 2011 and 2012 are still not definitively catalogued.

\begin{tabular}{cccc}
\hline Decades & $\begin{array}{c}\text { \# Eruptions in } \\
\text { the old catalogue }\end{array}$ & $\begin{array}{c}\text { \# Eruptions in the } \\
\text { updated database }\end{array}$ & $\Delta \#$ \\
\hline $1800-1809$ & 4 & 7 & 3 \\
$1810-1819$ & 6 & 7 & 1 \\
$1820-1829$ & 15 & 31 & 16 \\
$1830-1839$ & 22 & 41 & 19 \\
$1840-1849$ & 11 & 18 & 7 \\
$1850-1859$ & 15 & 32 & 17 \\
$1860-1869$ & 33 & 55 & 22 \\
$1870-1879$ & 25 & 38 & 13 \\
$1880-1889$ & 23 & 31 & 8 \\
$1890-1899$ & 25 & 36 & 11 \\
$1900-1909$ & 40 & 54 & 14 \\
$1910-1919$ & 23 & 37 & 14 \\
$1920-1929$ & 29 & 46 & 17 \\
$1930-1939$ & 28 & 49 & 21 \\
$1940-1949$ & 26 & 36 & 10 \\
$1950-1959$ & 20 & 35 & 15 \\
$1960-1969$ & 39 & 44 & 5 \\
$1970-1979$ & 32 & 38 & 6 \\
$1980-1989$ & 40 & 51 & 11 \\
$1990-1999$ & 48 & 65 & 17 \\
$2000-2009$ & & 82 & 82 \\
\hline TOTAL & 504 & 833 & 329 \\
\hline
\end{tabular}

tries, an increase of more than $50 \%$; Cordón Caulle was split into Puyehue-Cordón Caulle and Puntiagudo-Cordón Cenizos) and a total of 833 eruptions (see Table 1).

Although not explicit in the preceding work (Scalera, 2008), it is clear that the subdivision of the time-axis on a calendar year basis (using a minimum resolving power of $1 \mathrm{yr}$ ) is an artefact - dictated by a frequent lack of days and months for the catalogued onset and conclusion of eruptions - inapplicable in nature. This subdivision of time into a series of equal adjacent intervals lasting $1 \mathrm{yr}$ is necessary for the treatment of the data for drafting Fig. 1 and histograms like Fig. 2, but it introduces a "quantization" of the time-axis with some undesirable effects. For example, if the onset of an eruption is in November 1980 and the conclusion of the eruption in, say, March 1982, should the last three months be counted as activity in 1982 - totalling three years of eruptive activity - or should we disregard this "tail", and count only two years of activity? Many different alternatives are possible. However, when reanalysing the data the following set of five criteria were adopted: 


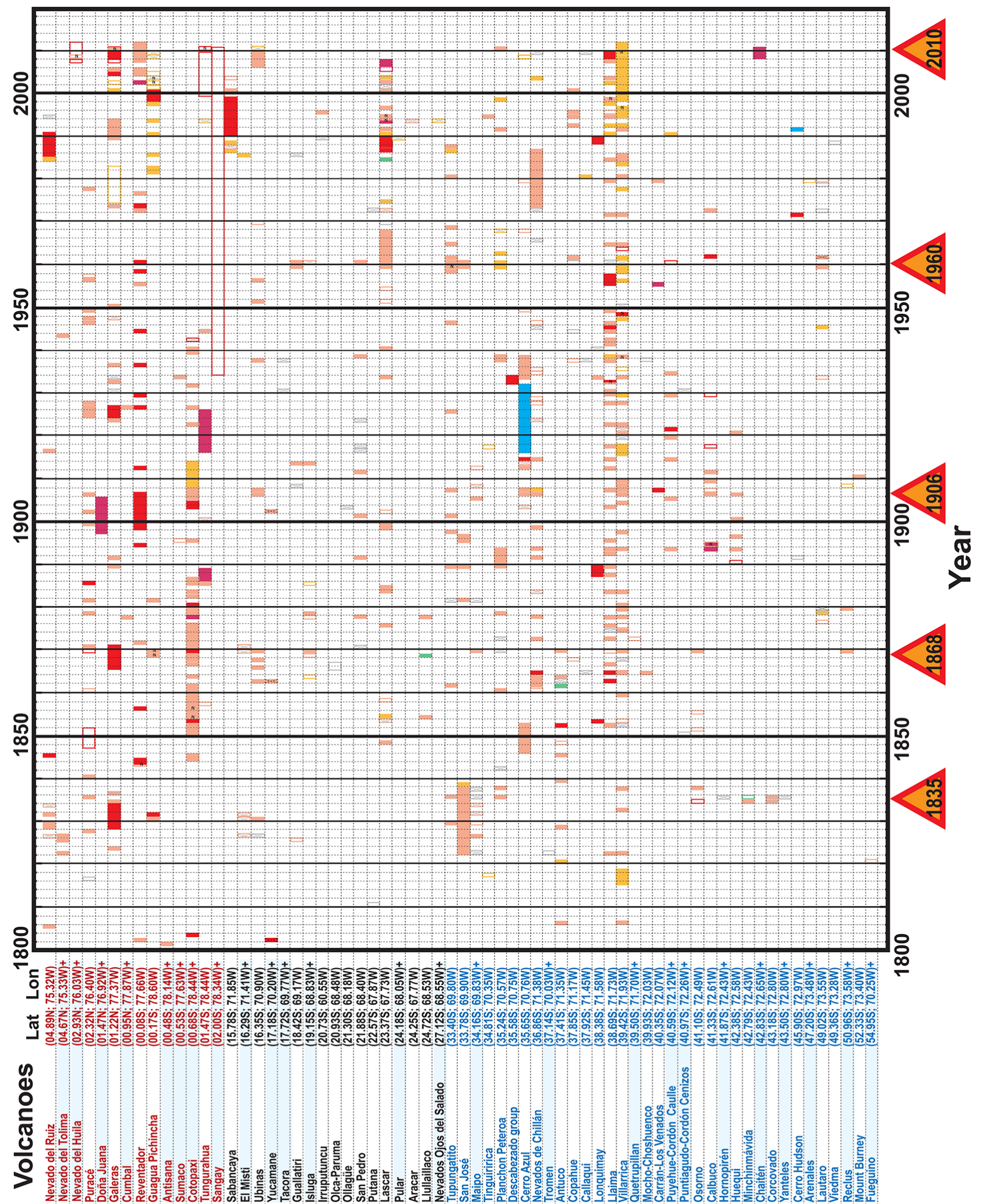

Fig. 1a. The complete catalogue of eruption data for the Andean belt from 1800 to 2010. The data was collected by the Smithsonian Institution (Siebert et al., 2011). Light blue bands mark the new entries in the volcanoes list compared to the data used in analysis a few years ago (Scalera, 2008). On the time axis 1800-2010 the eruptions are represented by rectangular bars, horizontal length of which is equal to the duration of the eruption and following the Volcanic Explosivity Index (VEI) colour scale on the right. The coloured names of the volcanoes are subdivided according to the three volcanic districts (northern-red, central-black, southern-blue). Counting the eruptions by years or triennium a graph like the following Fig. 2 can be drawn. 

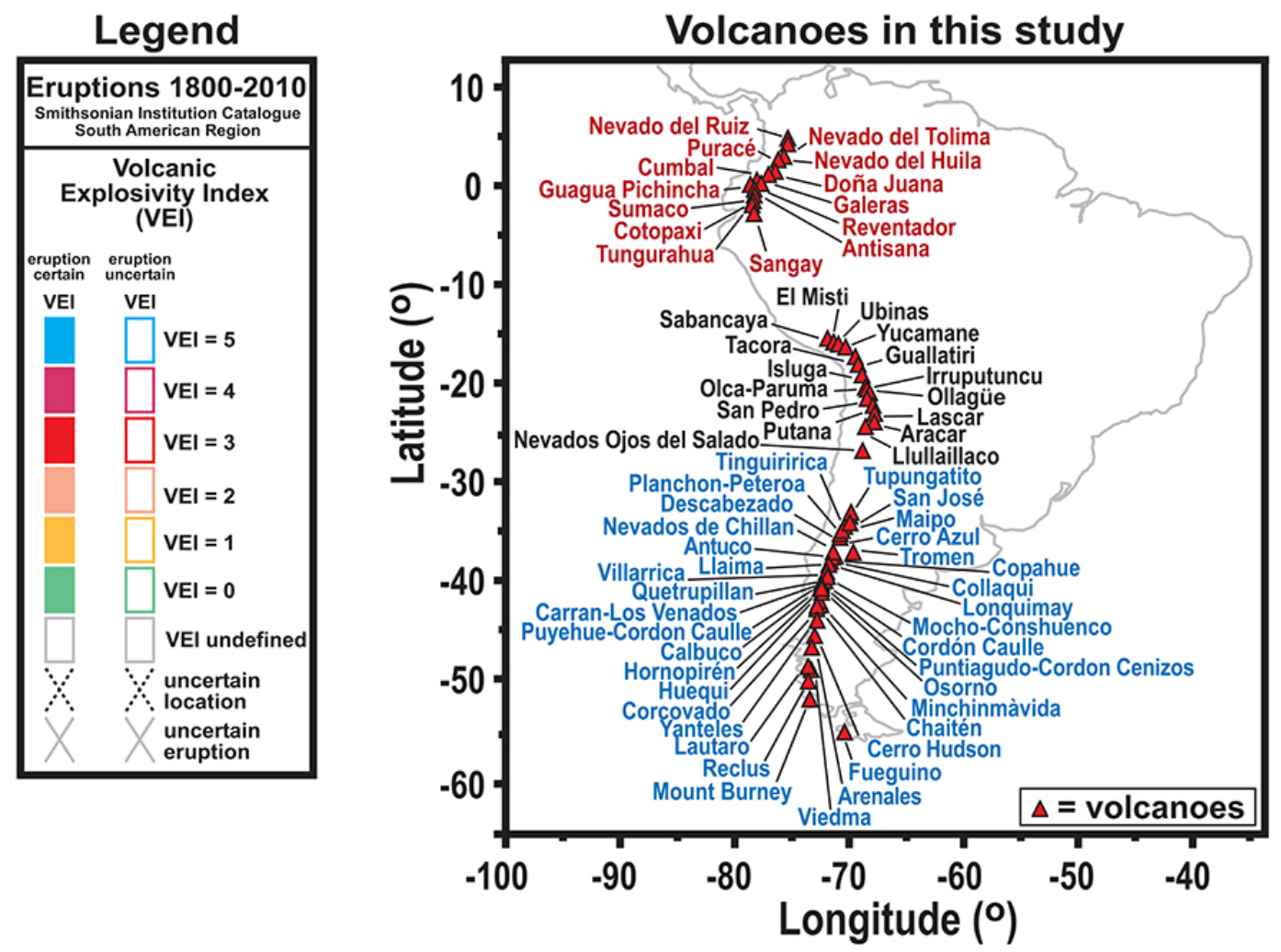

Fig. 1b. Legend and Map of South American Volcanoes relative to the complete catalogue of eruption data for the Andean belt from 1800 to 2010 represented in Fig. 1a. The coloured names of the volcanoes are subdivided according to the three volcanic districts (northern-red, central-black, southern-blue).

i. For calculating the duration (in years) of an eruption, the onset is shifted to January of the start year. Consequently a duration of, for example, one month or one day is counted as one. Durations of eleven, thirteen, and twenty-five months are counted as one, two, three years, respectively.

ii. If the onset month is unknown, it is assumed to have been July and the preceding rule (i) is applied.

iii. If the concluding month is unknown, it is assumed to have been June and the preceding rule (i) is applied.

iv. If the concluding year is unknown, the same onset year is assumed as the conclusion.

v. The value of the triennial rate of eruption is assigned to the last year of the triennium (while in Scalera, 2008, it was assigned to the central year).

Following these rules a complete reanalysis and reinterpretation of the data was performed. The new results are summarized in Figs. 1, 2, 3, and 4.

In Fig. 1, the complete set of eruption data is shown along the time axis from 1800 to the present time. The geographical locations of the volcanoes listed in Fig. 1a are plotted in Fig. 1b. The consequent histograms of eruptions per triennium is represented in Fig. 2, confirming the existence of spikes of higher eruption rates coinciding with major earthquakes of $M \geq 8.5$ (for comparison see the analogous figures in Scalera, 2008). The running period of three years was chosen because it offers a light moving average for the data, recording (point " $\mathrm{v}$ " of the rules) what happened before the end of the period. In Fig. 2 it can be inferred that there are major seismic events that are not associated with clearly increased eruption rates - a first small piece of evidence in favour of a cause-effect process from eruptions toward great earthquakes. In this study the details of 4 events of coincidence out of 5 events are discussed (instead of only 3 as in Scalera, 2008). Possibly this data set is still insufficient to arrive at a definitive conclusion but it can provide new clues about the geophysical processes involved. The four detailed plots of all the eruptions occurring in the four time intervals lasting from a few years before to a few years after the great earthquakes of 1868, 1906, 1960, 2010 are shown in Fig. 3a-d. The following discussion mainly analyses Figs. 3 and 4. 


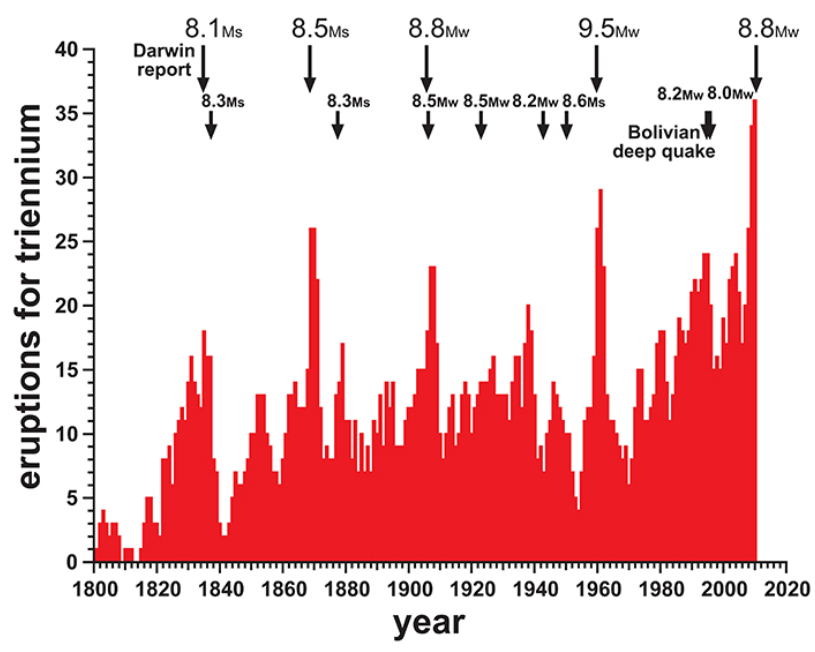

Fig. 2. Using the complete catalogue of eruption data for the Andean belt from 1800 to 2010, the triennial number of eruptions is plotted along the time axis. All non-discredited data have been used. Cusps of eruptions coinciding with the occurrence of highmagnitude earthquakes are confirmed, and an additional peak is correlated to the 2010 Maule quake $(M=8.8)$. Currently, no explanation exists for all the large fluctuations and marked minima in the eruption rate. In 1994, the occurrence of a very deep and strong seismic event in Bolivia $(M=8.2$; depth $=641 \mathrm{~km}$, data USGS, 2007) was preceded by a decade of increased eruptions rate.

\section{The volcano-seismic events in details}

\subsection{The 1868 event}

The 1868 earthquake $(M=8.5)$ occurred on 13 August, at 16:45 LT, near Arica, Chile. This case (Fig. 3d and Fig. 4d) is well after the period of marked incompleteness of the catalogue that characterized the first half of XIX century (which makes it impossible to analyse the preceding 1835 volcanoseismic event), but the lack of knowledge regarding the onset date of several eruptions, and considerations as to the cause of this ignorance can lead to some new reasoning. At that time, the news of recent and on-going eruptions was collected only by visual witnesses, either provided by inhabitants of areas close to the volcanic activity or people visiting to inspect the slopes of volcanoes and observing new active emissions or consolidated magma and ash flows. The start date for the eruptions may have been confused with the date of observation, displacing the event many months ahead and possibly one or more years ahead. This could be the case of the small set of eruptions of uncertain onset date grouped in 1869 (Fig. 3d).

The northern and southern volcanic districts were more strongly activated in this event, while one would have expected a greater activation of the central district (where the hypocentre was located). Static stress variation or viscoelastic relaxation are more likely to influence the near field, or a large region surrounding the event. This involvement of a remote volcanic district - in addition to the existence of great seismic events that are not associated with clear increases in eruption rates (Fig. 2) - is evidence for a more general cause acting on this phenomenon. The reason for the exclusion of dynamic stress as the main cause will become clear at the end of this discussion.

\subsection{The 1906 event}

This event (Fig. 3c and Fig. 4c) is complex because it is in fact two great earthquakes (Ecuador, 31 January; $M=$ 8.8; Lat $=01.0 \mathrm{~N}$, Lat $=81.5 \mathrm{~W}$; Chile, 16 August; $M=8.4$; Lat $=33.0 \mathrm{~S}$, Lon $=72.0 \mathrm{~W}$ ) that occurred in the same year, seven months and $3500 \mathrm{~km}$ apart. However, from Fig. 4c, the district that seems to be dominant is the southern one (light blue colour), totalling 19 eruptions in the time interval 19051908, while only 5 eruptions occurred in the northern district. In Fig. 3c two groupings of eruptions appear - the middle of 1906 and the middle of 1907. No increased volcanic activity is present in the interval 1902-1905. But there is a real possibility that this lack of eruptions may only be apparent. At least four eruptions (Huequi, Calbuco, Cerro Azul, Puracé) have unknown onset dates in 1906, and three (Nevados de Chillan, Llaima, Ubinas) in 1907. Therefore, considering the reasons explained above for the preceding 1868 volcanoseismic event (unreliable methods for determining eruption starting dates), the real distribution on the time axis may be very different, and it could be that some of the actual eruptions onsets occurred many months before or even one or two years earlier.

Considering that the greatest seismic event of 1906 was the Ecuador quake $(M=8.8)$, and that it occurred on the northern segment of the South American Pacific margin (map in Fig. 4c), the volcanic eruptions that started in the northern volcanic district were too few to be taken into consideration (Reventador continued an eruption from 1899 to an unknown month of 1906, and Puracé erupted as VEI $=2$ on a unknown date in 1906 or before) in a discussion of the mutual influence of eruption rates and earthquakes. Instead, an increased number of eruptions occurred (starting in 1906 and 1907 , but due to the assumed uncertainly of the starting dates, these could have been many months before) on the Chilean segment of the margin (southern volcanic district), near the hypocentral zone of the $M=8.4$ quake (Villarrica, Huequi, Calbuco, Cerro Azul, Nevado de Chillan, Tupungatito, Carran los Venados, Llaima, and a second time Villarrica and Cerro Azul). The possible redistribution of these southerndistrict eruptions on the time axis - towards earlier dates could ideally lead to a balance between the eruptions preceding the August $1906 M=8.4$ seismic event and the ones following it. But until a more precise set of data is found in historical archives regarding the actual starting times of individual eruptions, there is no way of resolving this problem in favour or against the precursory occurrence of an increased 


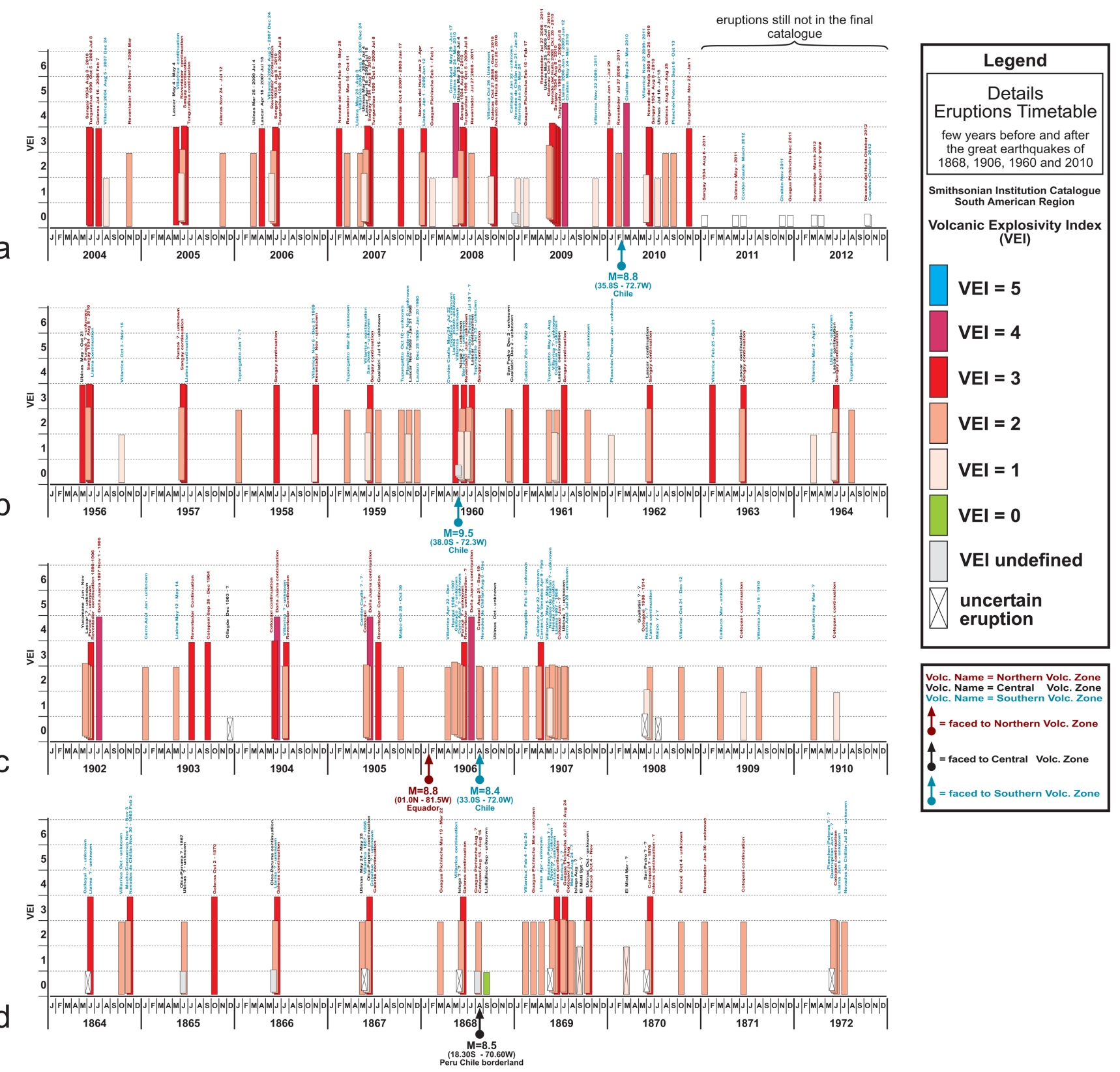

Fig. 3. Details of the eruptions that occurred few years before and after the major South American earthquakes. The VEI is represented both in colour and in length on the vertical axis. The details of the eruptions are shown for the 1868, 1906, 1960 and 2010 seismic events. The eruptions are identified by the name of the volcano and - if available - the starting and ending dates. The colour of the name is assigned as in Fig. 1. If, in the Smithsonian Institution Catalogue, the month of the starting date is not available, the bar representing the eruption is assigned arbitrarily to June or July of the same year. The occurrence of a greater rate of eruptions on the occasion of major earthquakes is observable in this plot, and a trend toward a precursory occurrence of a higher eruption rate is discernible passing from the oldest (1868) to the most recent (2010) correlation event. This can be seen with stronger evidence in the following Fig. 4 . The trend may be due to errors in assigning the years of the eruptions when modern technical facilities were lacking (see the discussion in the text). Although this trend was consolidated by the 2010 volcano-seismic event, a longer time lapse for collecting data is needed for more solidly grounded deductions.

eruption rate for this 1906 coincidence event. The data and their low quality (in the early decades of 20th century) still do not substantiate either of the two opposite cause-effect relationship, namely Eruptions-Earthquake or Earthquake-
Eruptions. Only a final joint scrutiny of the four volcanoseismic events might help resolve this dilemma. 

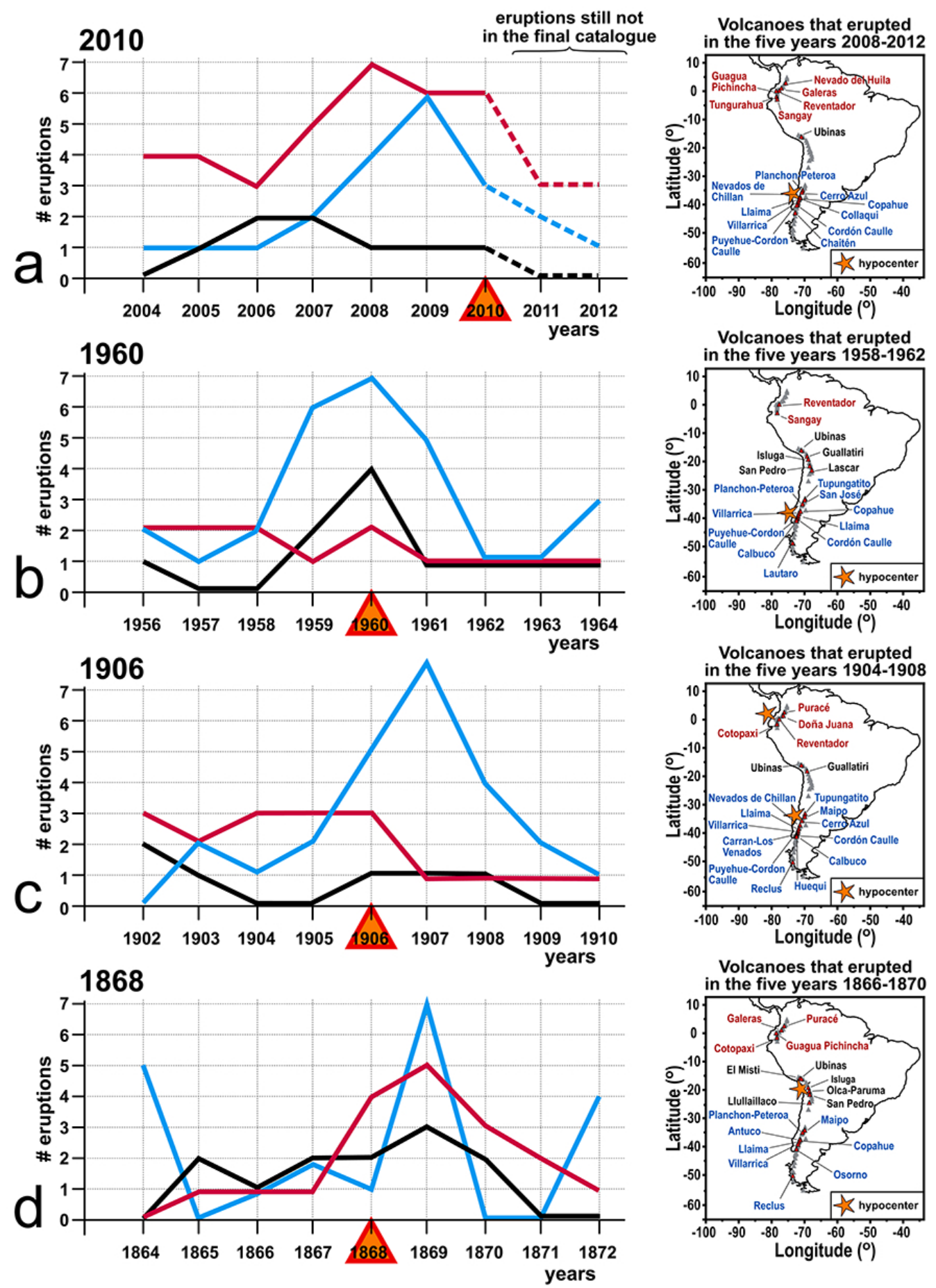

eruptions per year in the northern,
central and southern volcanic district

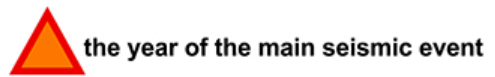

Fig. 4. Details of the eruption rates separated according to the three volcanic districts. The colours are assigned as in Fig. 1. The trend toward a precursory occurrence of a higher eruption rate is clear passing from the 1868 to the 2010 correlation event. The central volcanic district seems somewhat passive in producing high eruption rates, even on the occasion of the 1868 earthquake that occurred near the central district. The southern district was involved in all the four events. The higher eruption rates of both the northern and southern districts in 1868 and 2010 are evidence of a possible link with global geodynamic phenomena. 


\subsection{The 1960 event}

The strongest earthquake ever recorded (Chile, Sunday, 22 May 1960; Lat $=38.0 \mathrm{~S}$, $\mathrm{Lon}=72.3 \mathrm{~W}, M=9.5$ ) was well within the era of more modern scientific instrumentation (seismometry was by then more advanced) and surveying facilities (rapid transportation, aeroplanes, helicopters, etc., although landing difficulties to directly observe lava flows or debris were still cited in 1960 by Tazieff). The hypocenter was located facing the central part of the southern volcanic district, whose volcanoes - as can be seen in Fig. $4 \mathrm{~b}$ - were those most involved in the volcano-seismic correlation.

As occurred in the 1906 event, but less clearly, two grouping of eruptions appear along the time axis, mid 1960 and mid 1961. The few eruptions that occurred in the northern volcanic district can be considered unimportant for the present analysis (Fig. 3b and Fig. 4b) and the southern volcanic district dominated over the modest activation of the central district. The Sangay volcano continues its eruption from 1934 to the present day, and the other eruptions of the northern volcanoes do not exceed their normal background rate. Instead, an increase in the eruptions of the southern district can be seen in Fig. 4b. Tupungatito erupted several time from January 1958 to 1964, followed by some eruptions of Villarrica and then by San José, Planchon Peteroa, Lautaro, Cordon Caulle, Copahue, Llaima, and Calbuco. The southern district passed from one or two, to six eruptions in 1959, seven in 1960, and five in 1961. The central district's eruptions rose to four in 1960 .

What remains unresolved is the position on the time axis (Fig. 3b) of a few eruption onsets in 1959 (San José) and 1960 (Copahue, Llaima, Villarrica, Isluga, San José), which would have helped to better define the precursory character of the eruption rate. But at least a real jump from two to six eruptions can be clearly observed from 1958 to 1959 on the southern district, with a jump from zero to four in the interval 1958-1960 in the central district. In this case an increased number of eruptions before the great earthquake is claimable with certainty.

\subsection{The 2010 event}

The great Chile earthquake of 2010 occurred on Saturday, 27 February off the coast of the central Maule Region with a Magnitude $M=8.8$. This time (Fig. 3a and Fig. 4a) all the onset dates of the eruptive events are known thanks to improvements in satellite, aeronautical, and remote digital land surveillance methods. The rate of eruptions in the northern and southern volcanic district increased to 6-7 eruptions/year in 2008-2009.

The northern volcanic district became particularly active in the interval 2007-2009, while the central district with its one or two eruptions/year does not contribute to establishing this volcano-seismic correlation event. Therefore, the claim of increased volcanic activity in the northern and southern districts before the great earthquake of 2010 can be considered as well grounded. The higher eruption rates of both northern and southern districts should be considered as evidence for the global geodynamic nature of the phenomenon.

\subsection{Joint scrutiny of the four volcano-seismic events}

Passing from the older coincidence events to the 2010 case, a trend is clear - as soon as the data are more precisely located on the time axis - of an increased rate of eruptions before the main seismic events (Figs. 3 and 4). It needs to be checked whether this is a real trend or biased by some incompleteness of data. Taking all four volcano-seismic events of $1868,1906,1960$, and 2010 together, it can be deduced that going from oldest to most recent, the situation changes progressively from "great earthquake followed by many eruptions" towards "many eruptions preceding a large earthquake". This becomes clear for the correlation event of 1960 and extremely clear for 2010. Old, inaccurate methods of surveying and gathering news in order to establish the start of eruptions may be the reason for a systematic error that could postpone the onset of many eruptive events by months or even years. Obviously, the confirmation of this trend in favour of a precursory occurrence of an increased number of eruptions before a mega-earthquake must be confirmed by analysing the time axis distribution of future volcanic events and earthquakes on this active margin.

Confirmation of the occurrence of an increased number of eruptions before any future major South American Pacific margin earthquakes could make it reasonable to discard the hypothesis of an influence of dynamic stress in the activation of volcanic districts very remote from the hypocenter. Moreover, the presence of great seismic events not correlated to peaks of increased numbers of eruptions along the time axis (Fig. 2) is further strong evidence of the prevailing importance of volcanic events in driving the physical phenomenon that generates the volcano-seismic correlations.

\section{The relevance to emergencies management}

The possibility of forecasting the imminent occurrence of a potentially disastrous geophysical event has for a long time been seriously considered by the geosciences community (Nigg, 2000). A number of lists of candidate precursors of seismic or volcanic events exist, and the longest list is of seismic precursory phenomena (Caputo, 1987; among many others). But none of these seismic forecasting methods has been validated because of enduring insufficient statistical relevance of the association of the precursory event to the earthquake. Complex methodologies based on old ideas of "pattern recognition" (Keilis-Borok et al., 1988) are under experimentation (Panza et al., 2009), but a second phase of realworld application is still remote. 
Table 2. The recurrence of the volcano-seismic events. In the first column the years of the five events deducible from the sufficiently complete part of the Smithsonian Institution database (see Figs. 1 and 2). The elapsed time between two consecutive events is shown in the central column. The average recurrence between two consecutive events is $43.75 \mathrm{yr}$, with a $68 \%$ probability of re-occurrence of the events $\pm 8.5 \mathrm{yr}$, centered on the 43.75 th year after the last recorded event.

\begin{tabular}{ccc}
\hline $\begin{array}{c}\text { Year of event } \\
\text { occurrence }\end{array}$ & $\begin{array}{c}\text { Elapsed time } \\
\text { between events (yr) }\end{array}$ & $\begin{array}{c}\text { Average } \\
\text { recurrence (yr) }\end{array}$ \\
\hline 1835 & 33 & \\
1868 & 38 & $43.75 \pm 8.5$ \\
1906 & 54 & \\
1960 & 50 & \\
2010 & & \\
\hline
\end{tabular}

Is the eruptions-quakes correlation in some way relevant to prediction? It is necessary to try and answer the question: in which space window, which time window, and with what consequences could the event repeat in future. Clearly, the answer will only be satisfactory if an adequate contraction of the space-time-window of event occurrence is achieved.

In this practical case of the South-American correlation events the following main observations are:

i. The events have not stopped occurring since 1835 (a probable underestimated magnitude earthquake). Five events and four time intervals are available.

ii. The time window of $68 \%$ probability of re-occurrence of the events is $\pm 8.5 \mathrm{yr}$ centred on the 43.75 th year after the last recorded event (Table 2).

iii. In the more recent pair of cases - when the catalogue is more complete - an increased rate of eruptions has preceded the seismic event in some volcanic districts.

iv. The space window can be narrow in longitude but - due to peculiar characteristics of this correlationphenomenon - its latitudinal length can be in excess of $1500-2000 \mathrm{~km}$ in latitude (the maximum length of a volcanic district).

It is self-evident that, on the basis of the available data for the mean recurrence time, the time window cannot be contracted to a useful period of a few days or weeks. The "clock" of the correlation events is too vague, and currently it is impossible to establish whether their occurrences are subordinate to a unique mantle process, assuming this process could be hypothesized. Consequently, it cannot be stated with certainty that the large time intervals to date (four intervals observed) between two consecutive events will be repeated in future, or that in virtue of a possible (not refutable at the present time) independence of the regions and of the events, the time intervals could be reduced to a few years or even months.

Time lapses of $43 \mathrm{yr}$ are too long for use as a seismic alarm serving to induce a population to temporarily leave their homes. Clearly, forecasting would be excessively loose, but recognition of a long average interval between two consecutive events, and a standard deviation $\left(\sigma_{68} \%=8.5 \mathrm{yr}\right)$, could allow long-intermediate term planning of a series of preventive initiatives, mainly reinforcement of existing buildings and the progressive creation and maintenance of a coastal security strip in the tsunami prone areas, where no new houses should be built and existing ones should be removed or relocated.

On the other hand, even in the hope of implementing continuous counting of eruptions, the space window cannot be well defined. An attempt could be made to put the eruption rate of the whole Andean volcanic chain under constant observation (see the abstracts from the preconference book of O. Macedo on "Surveillance of Peruvian active volcanoes", and of J. Macharé on the "Role of the National Scientific Institutions in Natural Disaster Prevention in Peru"), and also to distinguish between the rates of the three volcanic districts. It might be hoped to identify the district in which eruptions are becoming more numerous but it would be impossible to reduce the latitudinal width of the emergency zone to narrower than the district itself without the support of other combined methods.

As can be deduced from Fig. 4, the complexity of this phenomenon is greater than expected. With reference to the new updated catalogue, in the 1868 case all the districts were activated (Fig. 4d) but mainly the two adjacent to the one in which the seismic event occurred (the northern and the southern). In 1906, the main event (31 January, $M=8.8$ ) was located in the northern district, but (Fig. 4c) the main increase in volcanic activity was recorded in the southern district, probably linked to the August Chilean $M=8.5$ event. The 1960 earthquake seems to be linked to a major activation of southern volcanism with a diminishing increase in eruption rates in the central and northern districts, rather grossly proportional to the distance (Fig. 4b). Finally, in the years preceding the 2010 seismic event, which occurred on the southern district region (Fig. 4a), it was the northern district that was strongly activated (more clearly from 2007), followed in 2008-2009 by the southern one. Despite the consequent impossibility of associating an enhancement of the eruption rate of a specific district to an earthquake occurred in the same district, the volcano-seismic correlation events occur with their typical peaks of volcanic activity, as shown in Fig. 2.

A further difficulty for a possible prediction methodology derives from deep earthquakes, like the Bolivian event of 1994. In the time series in Fig. 2 a ramp of increasing eruption rate per triennium is discernible, beginning almost to exceed the background in 1983 . The triennial eruption rate 
in Fig. 2 reached a peak value of 24 eruptions in 1994, which is greater than the rate associated with the 1906 event (the 1868, 1960, and 2010 events reached 26, 29 and 31 eruptions, respectively). A false alarm would be launched if as alarm criterion was adopted the reaching or excess of, for example, a 23 eruption triennial rate (the minimum peak rate of the 1906 event). The question remains whether or not this kind of false alarm could be avoided.

More in-depth studies are therefore needed, and it can only be hoped that in the future forecasting (with narrower time and space windows) will be possible in "joint venture" with additional methods (e.g. gaps, pattern recognition, etc.; see Gelfand et al., 1976; Caputo et al., 1980; Keilis-Borok et al., 1988; Panza et al., 2009; among others).

\section{A link to global geodynamics}

The apparently complex behaviour of the region indicates some fundamental process still not fully understood. It is important to note that this behaviour cannot be adequately explained within a framework of plate tectonics. This is because it is impossible to correlate a major production of magmatic materials without a major production of frictionheat associated with the seismic events produced by subduction, making it impossible to sustain the implausible causal earthquake-to-eruptions chain. The cooperation of all the districts in the expression of the phenomenon is a clue of its origin in a general tectonic process. This "cooperation" does not fit within the currently accepted framework because of the incompatible geometry of the Nazca plate boundaries and its transform fault intersections with the Andean Pacific margin, in relation to the northern and southern volcanic districts. The above cited views of Latter (1971) seem more realistic, and a preceding paper by Scalera $(2006,2012 a)$ could be linked to the described phenomena in a general way. A slowly pulsating expansion could be the common cause of phenomena so far considered independent of each other. An integrated solution (Scalera, 2012b) could interpret the oscillatory behaviour of the TPW, of Polar Motion, with its direction towards South America, the same trend towards Nazca of the chains of volcanic edifices of the Pacific, and the so called 'Neotectonic Period' (Ollier, 2003; Scalera, 2010) as all produced by pulsations and effects on different time scales of the Earth's expansion.

Polar Motion (PM) and True Polar Wander (TPW) are two phenomena that plate tectonics tends to consider as independent processes. Polar Motion is explained by hypothesizing a subtraction of mass due to the melting of the ice cap in the Northern Hemisphere mainly on the Canadian Shield. This slow deglaciation cannot be extrapolated by more than $1 \mathrm{Myr}$ in the past, while it is necessary to reconnect PM to a TPW that has been in progress for hundreds of millions years. Attempts have been made to ascribe TPW to advections of mass related to geoidal shape, patterns of which are impos- sible to know in the remote geological past (Steinberger and O'Connel, 1997). When two phenomena clearly of the same origin are kept separate by a theory, this is a sign of a serious lack of coherence in the theory itself.

This anomaly can be resolved in the asymmetric expanding Earth schema by assuming an emplacement of mass in the Southern Hemisphere in the Nazca region. In this interpretation the TPW path through geological time, with its stasis at $50 \mathrm{Myr}$ and subsequent inversion of sense (Besse and Courtillot, 1991, 2002; see figures in Scalera, 2006, 2012a, 2012b) when the region of the maximum expansion passed the equator, is naturally linked to the position of the region of maximum planetary expansion and unbalanced emplacement of mass in the global paleogeography of the expanding Earth framework (Scalera, 2006, 2012b). It should be remembered that many other asymmetries of the deep Earth have recently been discovered (Aubert et al., 2008; Garnero and McNamara, 2008; Wookey and Helffrich, 2008; Monnereau et al., 2010), and the possibility remains that most of them could be associated in a unique explanation in the ambit of planetary expansion.

Consequently, in this view, possible pulsations in the extrusion of new mass in the Nazca region could be associated with increasing or declining eruption rates along the Andean volcanic belt. Evidence in favour of this is the involvement of both of the northern and the southern volcanic districts in the correlation events (Fig. 4), both districts being ideally crossed by the Nazca's expanding ridge perimeter.

A more strict relation should then be expected between the peculiar South American volcano-seismic phenomena and the geodynamic signal provided by PM-TPW. Since a periodicity of a few decades is characteristic of both the volcano-seismic events and the Markowitz oscillation (Poma et al., 1991) a possible synchronicity between these phenomena should be sought (Fig. 5a). This kind of geodynamic correlation among different phenomena should not be surprising: an analogous correlation has already been detected in North America (Cascadia region), involving seismic tremors, geodetically measured slip and Chandler Wobble period $(\approx 14$ months). The correlation was first revealed by Rogers and Dragert (2003) for the time period 1997-2003, without recognizing the role of the Chandler Wobble. The phenomenon was later confirmed by Rubinstein et al. (2010), who noted synchronicity with the PM polhody period of 14 months but claimed irrelevance of PM periodicity in driving the correlation (Fig. 5c).

Following this line of reasoning, the same plot in Fig. 5a shows both the secular polar motion (a suitable running average was applied to all the PM data from 1846 to 2009; data from IERS web facilities) and the time of occurrence of the volcano-seismic correlation events.

Only three volcano-seismic events can be correlated to the 1846-2009 series of PM data, namely the events of 1906, 1960 and 2010 (Fig. 5a). The PM data preceding 1900 are not homogeneous with the 1900-2009 data, and the PM path 


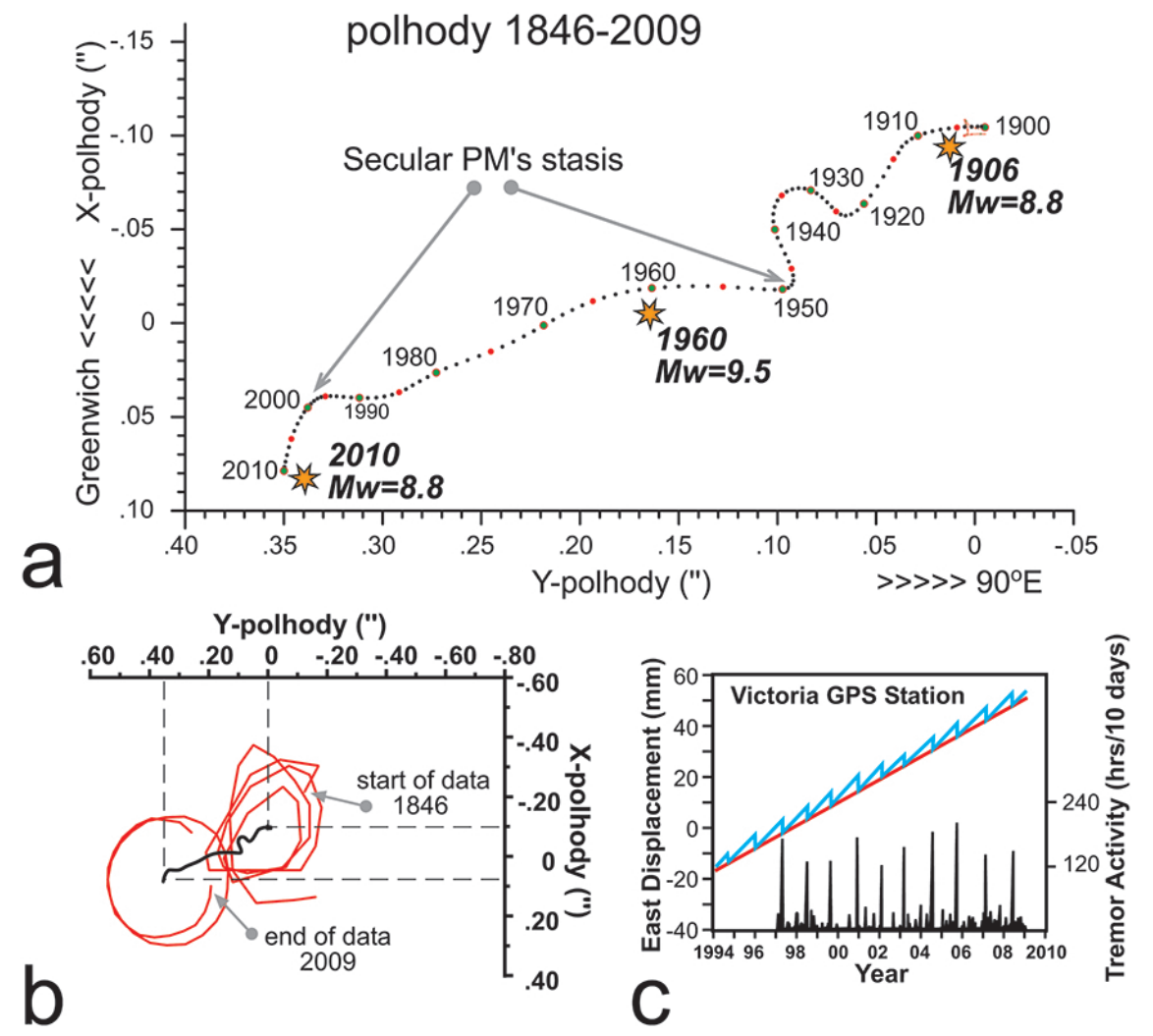

Fig. 5. (a) Oscillating path of the Secular Polar Motion starting from the earliest available data (1846). The data before 1900 exhibit an inextricable loop (in red) and they are not homogeneous with the 1900-2010 series. The three stars represent the times of the volcanoseismic correlation events along the secular PM path. The correlation events of 1960 and 2010 occur ten years after a lustrum of nearly total stasis of the PM (in 1945-1950 and 1995-2000), but this cannot be observed for the 1906 event because of the unreliability of the pre-1900 PM data. (b) Comparison between the low quality data before 1900 and higher quality modern data. The polhody (in red) a few years starting from 1846 and a few years before 2009 is fully represented beside the secular path of the centre of the polhody. Modern and oldest PM astrogeodetic data also differ in the methodology of acquisition. The radius of the PM's spiralling (Chandler Wobble with $\approx 14$ months period) fluctuates between a few meters and about $15 \mathrm{~m}$, while the total journey of the Secular PM is about $30 \mathrm{~m}$. (c) An analogous correlation (the graph is redrawn from Rubinstein et al., 2010) exists between a shorter frequency in PM (the $\approx 14$ months period) and other geophysical phenomena in the North America Cascadia region - see the text for explanations.

from 1846 to 1900 is not reliable for any form of interpretation. The events of 1960 and 2010 occur about $12 \mathrm{yr}$ after a five-year window of "stasis" in the secular PM (a very low velocity, witnessed by the extreme proximity of the annual averaged points in the plot). While the data do not contradict the same mutual pattern between the event of 1906 and the PM data of the last decade of the XIX century, the non-homogeneity of data do not permit a positive conclusion (Fig. 5b). Therefore, only two mutual correlations can be envisaged between volcano-seismic events and PM. To ascertain the reality of this additional intriguing correlation (or synchronism with the Markowitz oscillation of PM) a larger number of volcano-seismic events are needed. This kind of natural phenomena over extended temporal scales is suitable for study by future generations of geoscientists. The next volcano-seismic correlation is expected to occur within $40-50$ yr.

\section{Conclusions}

A reanalysis of the Smithsonian Institution data for the South American region on the basis of a number of new entries in the listed volcanoes and the last great Chilean earthquake of February 2010, confirmed the occurrence of peculiar volcano-seismic events with a mean return time of $\approx 43$ yr. Historic thinkers were convinced that, as regards this subject and region, there was a triggering relationship from earthquakes to eruptions, but a detailed analysis, with additional discrimination in three volcanic districts, produces grounded evidence for a precursory increase in the eruption rate passing from the old incomplete catalogue (recording popular hearsay accounts or otherwise imperfect eruptions onset dates) to the modern one (derived from Volcanology Observatories, satellite data, and aeronautical observations). 
This evidence will require reinforcement from analogous investigations into future volcano-seismic events.

This time-relation between eruptions and earthquakes cannot be generalized to other regions of the Earth but can at least be of some help to the South American Civil Defence in programs for disaster prevention. The use of this precursory phenomenon as an individual tool for deterministic forecasting is not possible. Possibly, only the awareness of having entered a period of increased rate of eruptions can be established. This should not be considered a pessimistic position, but only an admission that the recorded real cases are still too few, with the presumption that future occurrences of volcano-seismic correlation events will be occasions to refine this knowledge and increase functional know-how for an eventual prediction project.

Nevertheless, information about increasing eruption rates should be provided to a wider forecasting program, like the pattern recognition program (Gelfand et al., 1976; Caputo et al., 1980; Keilis-Borok et al., 1988; Panza et al., 2009; among many others), in which other clues are mutually considered, like seismic gaps, general seismicity patterns, deep seismicity occurrences, etc. Only this or other more general research programs might eventually restrict the eligible emergency zones. On the South American Pacific margin, information of a rising eruption rate would be of invaluable importance for pattern recognition methods and for Civil Defence Authorities. In this perspective, some further centuries of datacollecting will be required to establish a more substantial solution and hopefully develop new perspectives on natural disaster prevention and forecasting.

In science it is important not only to resolve problems but also to propose new hypotheses. A very promising possibility is to link occurrence of volcano-seismic events to the general geodynamic behaviour of the Earth. On the basis of the similar periods of recurrence and the explanatory possibilities opened by an asymmetric expansion of the Earth (Scalera, 2012a, b), in particular concerning the secular PM path and the maximum Earth expansion rate on the Nazca region, a degree of synchronicity can be postulated between some characteristics of the Markowitz oscillation of the PM and the time series of the volcano-seismic events (Fig. 5). This possible synchronicity must again be confirmed or confuted by future centuries of data. In the case of a future confirmation, this would be the first example of a relationship between the extremely deep Earth (Markowitz oscillation is thought to be caused by flows near the core-mantle boundary) and the surface phenomena of an asymmetrical expanding Earth (Scalera, 2012b).

The progress that was hoped for, can be achieved only by adopting a new, more realistic geodynamic theory, which can only be an expanding Earth. It is also necessary that awareness of the South American phenomenon of volcanoseismic correlation becomes a more generally known concept. In this respect, a great writer, Antoine de Saint-Exupery (1900-1944), has already shown that the "volcanic chorus" can become part of general culture and that literature, poetry, music, and science can be nicely mixed:

On le subit avec surprise dans ce paysage désaffecté, où mille volcans se répondaient l'un l'autre, de leurs grandes orgues souterraines, quand ils crachaient leur feu (We are astonished in this disaffected landscape, where a thousand volcanoes answer each other, with their huge underground organs, when they spit their fire) (de Saint-Exupery, 1939, Terre des hommes, in a chapter describing a flight along Andes).

The same "volcanic chorus" also greatly impressed Charles Darwin:

When I compared the dates of these three [volcanic] events, I was astonished to find that they agreed within less than six hours of each other. Aconcagua is only 480 miles north of Osorno, but Coseguina is about 2700 north of Aconcagua. It may be asked, were these three eruptions, which burst through the same chain of mountains, in any respect connected, or was the coincidence accidental? We cannot be too cautious in guarding against the assumption that phenomena are connected, because they happen at periods bearing some determined relation to each other. (Darwin, 1840)

Acknowledgements. Guido Chiesura has implemented the author's awareness about the Darwin meditations on the South American region. I am grateful to Angelo Poma for discussions and suggestions about the Polar Motion data series. Ken Tokeshi, Franck Audemard and an anonymous referee have helped in improving this paper, providing many corrections and invaluable suggestions. The author thanks his colleagues Bruno Zolesi and Paolo Favali who supported his participation at the Cusco Conference.

Edited by: K. Tokeshi

Reviewed by: F. Audemard and one anonymous referee

\section{References}

Acharya, H.: Volcanic activity and large earthquakes, J. Volcanol. Geotherm. Res., 86, 335-344, 1982

Aubert, J., Amit, H., Hulot, G., and Olson, P.: Thermochemical flows couple the Earth's inner core growth to mantle heterogeneity, Nature, 454, 758-761, 2008.

Barrientos, S. E.: Large thrust earthquakes and volcanic eruptions, Pure Appl. Geophys., 142(1), 225-237, 1994.

Besse, J. and Courtillot, V.: Revised and synthetic Apparent Polar Wander Paths of the African, Eurasian, North American and Indian Plates, and True Polar Wander since 200 Ma, J. Geophys. Res., 96, 4029-4050, 1991.

Besse, J. and Courtillot, V.: Apparent and true polar wander and the geometry of the geomagnetic field over the last $200 \mathrm{Myr}$, J. Geophys. Res., 107(B11), 2300, doi:10.1029/2000JB000050, 2002.

Blot, C.: Relations entre les séismes profonds et les eruptions volcaniques au Japon, Bull. Volcan., 28(1), 25-63, 1965.

Blot, C. and Priam, R.: Volcanisme et séismicité dans l'Archipel des Nouvelles-Hébrides, Bull. Volcan., 26(1), 167-180, 1963. 
Caputo, M.: Sismologia e segnali precursori dei terremoti, Calderini Press, Bologna, 184 pp., 1987.

Caputo, M., Keilis-Borok, V., Oficerova, E., Ranzman, E., Rotwain, I., and Solovieff, A.: Pattern recognition of earthquake-prone areas in Italy, Physics of Earth and Planetary Interiors, 21, 305$320,1980$.

Carr, M. J.: Volcanic activity and great earthquakes at convergent plate margins, Science, 197, 655-657, 1977.

Casertano, L.: Sui fenomeni sismo-vulcanici del Sud del Chile, Annali Osservatorio Vesuviano, 4 (serie 6), Napoli, 17 figs., VII Tav., 189-216, 1962.

Casertano, L.: General characteristics of active Andean volcanoes and a summary of their activities during recent centuries, B. Seismol. Soc. Am., 53(6), 1415-1433, 1963.

Critikos, N. A.: Relazioni fra i fenomeni sismici e le manifestazioni vulcaniche nel mar Egeo e nella Grecia Orientale, Pure Appl. Geophys., 8(1-2), 145-159, 1946.

Darwin, C.: Journal of Researches into the Geology and Natural History of the various countries visited by H.M.S. Beagle, under the command of Captain Fitzroy, R.N. from 1832 to 1836 . H. Colburn, Great Malborough Street, London, 1839.

Darwin, C.: On the connexion of certain volcanic phenomena in South America; and on the formation of mountains chains and volcanoes, as the effect of the same power by which continents are elevated, Transaction of the Geological Society of London, 2d ser., pt. 3(5), 601-631 (reprinted in: The collected papers of Charles Darwin, edited by: Barrett, P. H., The University of Chicago Press, Chicago, 1977, 326 pp.), 1840

de Saint-Exupery, A.: Terre des hommes, Éditions Reynald et Hitchcock, 1939.

Engdahl, E. R., van der Hilst, R. D., and Buland, R. P.: Global teleseismic earthquake relocation with improved travel times and procedures for depth determination, B. Seismol. Soc. Am., 88, 722-743, 1998.

Garnero, E. J. and McNamara, A. K.: Structure and Dynamics of Earth's Lower Mantle, Science, 320, 626-628, 2008.

Gelfand, I. M., Guberman, Sh. A., Keilis-Borok, V. I., Knopoff, L., Press, F., Ranzman, E. Ya., Rotwain, I. M., and Sadovsky, A. M.: Pattern recognition applied to earthquake epicenters in California, Physics of the Earth and Planetary Interiors, 11, 227-283, 1976.

Hill, D. P., Pollitz, F., and Newhall, C.: Earthquake-Volcano interactions, Phys. Today, 55 (November), 41-47, 2002.

Hull, E.: Volcanoes: Past and Present, Scott \& Scribner, London \& New York, 270 pp., 1904.

Kanamori, H. and Brodsky E. E.: The physics of earthquakes, Phys. Today, 54 (June), 34-40, 2001.

Keilis-Borok, V. I., Knopoff, L., Rotwain, I. M., and Allen, C. R.: Intermediate-term prediction of occurrence times of strong earthquakes, Nature, 335, 690-694, 1988.

Kimura, M.: Major magmatic activity as a key to predicting large earthquakes along the Sagami Trough, Japan, Nature, 260, 131133, 1976.

Klohn, E.: The February 1961 eruption of the Calbuco volcano, B. Seismol. Soc. Am., 53(6), 1435-1436, 1963.

Lara, L. E., Naranjo, J. A., and Moreno, H.: Rhyodacitic fissure eruption in Southern Andes (Cordòn Caulle; $40.5^{\circ} \mathrm{S}$ ) after the 1960 (Mw:9.5) Chilean Earthquake: a structural interpretation, J. Volcanol. Geoth. Res., 138, 127-138, 2004.
Latter, J. H.: The interdependence of seismic and volcanic phenomena: Some space-time relationships in seismicity and volcanism, Bull. Volcan., 35(1), 127-142, 1971.

Linde, A. T. and Sacks I. S.: Triggering of volcanic eruptions, Nature, 395, 888-890, 1998.

Manga, M. and Brodsky, E.: Seismic triggering of eruptions in the far field: volcanoes and geyser, Annu. Rev. Earth Planet. Sci., 34, 263-291, 2006.

Monnereau, M., Calvet, M., Margerin, L., and Souriau, A.: Lopsided Growth of Earth's Inner Core, www.sciencexpress.org, 15 April 2010, Science.1186212, 8 pp., 2010.

Nigg, J. M.: Predicting earthquakes: Science, pseudoscience, and public policy paradox, in: Prediction: science, decision making, and the future of nature, edited by: Sarewitz, D. R., Pielke, R. A., and Byerly, R., Island Press, 135-156, 2000.

Nostro, C., Stein, R. S., Cocco, M., Belardinelli, M. E., and Marzocchi, W.: Two-way coupling between Vesuvius eruptions and southern Apennine earthquakes, Italy, by elastic stress transfer, J. Geophys. Res., 103(B10), 24487-24504, 1998.

Ollier, C. D.: The origin of mountains on an expanding Earth, and other hypotheses, in: Why Expanding Earth? - A book in Honour of Ott Christoph Hilgenberg, edited by: Scalera, G. and Jacob, K.-H., Proceedings of the 3rd Lautenthaler Montanistisches Colloquium, Mining Industry Museum, Lautenthal (Germany), 26 May 2001 (INGV Publication, Rome), 129-160, 2003.

Panza, G. F., Peresan, A., and Vaccari, F.: La previsione dei terremoti: stato dell'arte, Geoitalia, 28, 18-23, 2009.

Poma, A., Proverbio, E., and Uras, S.: Decade Fluctuations in the Earth's Rate of Rotation and Long-Term Librations in Polar Motion, Il Nuovo Cimento C, 14(2), 119-125, 1991.

Rogers, G. and Dragert, H.: Episodic tremor and slip on the Cascadia subduction zone: The chatter of silent slip, Science, 300 , 1942-1943, 2003.

Rubinstein, J. L., Shelly, D. R., and Ellsworth, W. L.: Non volcanic tremor: A window into the roots of fault zones, in: New Frontiers in Integrated Solid Earth Sciences, edited by: Cloetingh, S. and Negendank, J., International Year of Planet Earth, Springer Science + Business Media, 287-314, 2010.

Scalera, G.: TPW and Polar Motion as due to an asymmetrical Earth expansion, in: Frontiers in Earth Sciences: New Ideas and Interpretations, edited by: Lavecchia, G. and Scalera, G., Ann. Geophys.-Italy, Supplement to Vol. 49(1), 483-500, 2006.

Scalera, G.: A new model of orogenic evolution, Rend. Soc. Geol. It., Nuova Serie, 5, 214-218, 2007a.

Scalera, G.: South American Pacific margins key target for geosciences and general culture, New Concepts in Global Tectonics Newsletter, n.43, June, 60-68, 2007b.

Scalera, G.: Geodynamics of the Wadati-Benioff zone earthquakes: The 2004 Sumatra earthquake and other great earthquakes, Geofísica Internacional, 46(1), 19-50, 2007c.

Scalera, G.: Great and old earthquakes against great and old paradigms - paradoxes, historical roots, alternative answers, Adv. Geosci., 14, 41-57, doi:10.5194/adgeo-14-41-2008, 2008.

Scalera, G.: Earthquakes, phase changes, fold belts: from Apennines to a global perspective, GeoActa, Special Publication n.3 "Geology of the Adriatic area", 25-43, 2010.

Scalera G.: Is plate tectonics a Tychonian compromise?, Z. Geol. Wissenschaft., 40(1), 19-34, 2012a. 
Scalera G.: Distensional Mediterranean and World Orogens - Their Bearing to Mega-Dykes Active Rising, in: The Earth Expansion Evidence - A Challenge for Geology, Geophysics and Astronomy, edited by: Scalera, G., Boschi, E., and Cwojdziński, S., Selected Contributions to the Interdisciplinary Workshop of the 37th International School of Geophysics, EMFCSC, Erice (4-9 October 2011), 115-160, 2012b.

Siebert, L., Simkin, T., and Kimberly P.: Volcanoes of the World, 3rd Edn., Smithsonian Institution \& University of California Press, 568 pp., 2011.

Steinberger, B. and O'Connel, R. J.: Changes of the Earth's rotation axis owing to advection of mantle density heterogeneities, Nature, 387, 169-173, 1997.

Tazieff, H.: Quelques observations sur la crise séismo-volcanique de mai 1960 au Chili central, Bull. Volcan., 24(1), 83-86, 1962.
Uffen, R. J. and Jessop, A. M.: The stress release hypothesis of magma formation, Bull. Volcan., 26(1), 57-66, 1963.

Walter, T. R.: How a tectonic earthquake may wake up volcanoes: Stress transfer during the 1996 earthquake-eruption sequence at the Karymsky Volcanic Group, Kamchatka, Earth Planet. Sc. Lett., 264, 347-59, 2007.

Walter, T. R. and Amelung, F.: Volcanic eruptions following M9 megathrust earthquakes: Implications for the Sumatra-Andaman Volcanoes, Geology, 35(6), 539-542, 2007.

Wookey, J. and Helffrich, G.: Inner-core shear-wave anisotropy and texture from an observation of PKJKP waves, Nature, 454, 873876, 2008. 